\title{
Electrochemical oxidation of butyl paraben on boron doped diamond in environmental matrices and comparison with sulfate radical-AOP
}

(1)

(1)

Noelia Pueyo ${ }^{\mathrm{a}}$, Maria P. Ormad ${ }^{\mathrm{a}}$, Natividad Miguel ${ }^{\mathrm{a}}$, Petros Kokkinos ${ }^{\mathrm{b}}$, Alexandra Ioannidi ${ }^{\mathrm{b}}$, Dionissios Mantzavinos $^{\mathrm{b} *}$, Zacharias Frontistis $^{\mathrm{c}}$

${ }^{a}$ Department of Chemical Engineering \& Environmental Technologies, University of Zaragoza, C/María de Luna 3, Zaragoza, 50018, Spain

${ }^{\mathrm{b}}$ Department of Chemical Engineering, University of Patras, Caratheodory 1, University Campus, GR-26504 Patras, Greece

${ }^{\mathrm{c}}$ Department of Chemical Engineering, University of Western Macedonia, GR-50132 Kozani, Greece

* Corresponding author:

Email: mantzavinos@chemeng.upatras.gr; Tel.: +302610996136

\section{Abstract}

The electrochemical oxidation (EO) of butyl paraben (BP) over boron-doped diamond (BDD) anode was studied in this work. Emphasis was put on degradation performance in various actual water matrices, including secondary treated wastewater (WW), bottled water (BW), surface water (SW), ultrapure water (UW), and ultrapure water spiked with humic acid (HA). Experiments were performed utilizing $0.1 \mathrm{M} \mathrm{Na}_{2} \mathrm{SO}_{4}$ as the electrolyte. Interestingly, matrix complexity was found to favor BP degradation, i.e. in the order $\mathrm{WW} \sim \mathrm{BW}>\mathrm{SW}>\mathrm{UW}$, thus implying some kind of synergy between the water matrix constituents, the reactive oxygen species (ROS) and the anode surface. The occurrence of chloride in water matrices favors reaction presumably due to the formation of chlorine-based oxidative species, and this can partially offset the need to work at increased current densities in the case of chlorine-free electrolytes. No $\mathrm{pH}$ effect in the range 3-8 on degradation was recorded. EO oxidation was also compared with a sulfate radical process using carbon black as activator of sodium persulfate. The matrix effect was, in this case, detrimental (i.e. $U W>B W>W W$ ), pinpointing the different behavior of different processes in similar environments. Keywords: aqueous matrix; anodic oxidation; carbocatalysis; electrolytes; emerging contaminants; persulfate

\section{Introduction}


Advanced oxidation processes (AOPs, e.g. heterogeneous and homogeneous photocatalysis, electrochemical oxidation (EO), ozonation, ultrasound irradiation, Fenton and alike reactions, amongst others) have been investigated for the removal of emerging organic pollutants during the last decades (Klavarioti et al., 2009). Micropollutants' removal from water matrices has been recognized as an important environmental and health issue. Water matrix may exert influence on the electrochemical treatment on boron-doped diamond (BDD) anode. This is due to the high concentrations of numerous interfering organic and inorganic species, which are usually present in real effluent samples (Tsantaki et al., 2012). So far, the majority of studies concerning the application of AOPs for water/wastewater treatment have been performed (and still are) in ultrapure water. The rationale behind this is associated with the need to obtain basic knowledge with respect to the degradation kinetics, mechanisms and pathways excluding the water matrix effect. Nonetheless, the effect itself may be unpredictably important, thus leading to erroneous conclusions. In most cases, treatment efficiency decreases with increasing water matrix complexity. This is due to the fact that the target pollutant is likely to compete with the non-target constituents of the matrix (e.g. organics, inorganics and microorganisms) for the precious oxidant species, as well as (in the case of heterogeneous processes) for the active sites of the catalysts/activators (Frontistis and Mantzavinos, 2017). In the study of Kenova et al. (2018), on the electrooxidation of Mordant Blue 13 azo dye in different water matrices, both electrode material and water matrix parameters have been reported to significantly affect COD removal and dye decolorization.

Electrochemical oxidation has emerged as an environmentally clean technology and BDD has been shown to be one of the most auspicious anodes for environmental applications (Frontistis et al., 2017; Sarkka et al., 2015). BDD anodes are known to enhance the generation of ROS compared to other anodic materials (Pecková et al., 2009); this facilitates the effective conversion of organic micropollutants of emerging concern and, subsequently, their mineralization. However, the exact mechanisms of $\mathrm{O}_{2}$ and ${ }^{\circ} \mathrm{OH}$ production have not been completely elucidated (Henke et al., 2019; Kraft et al., 2003).

Sulfate radical oxidation processes (SR-AOPs) have recently been developed for water treatment. Sulfate radicals can be produced after activation of compounds belonging to the group of persulfates. Activation can occur via numerous methods including, amongst others, heat, transition metals, light irradiation and ultrasound irradiation (Matzek and Carter, 2016). In recent years, metal-free carbonaceous materials have been proposed as alternative catalytic materials for environmental applications (Abid et al., 2016), including persulfate activation. Activated carbon, graphene, multi-walled carbon nanotubes and biochars are some characteristic examples. Carbon black (CB), mainly consisting of fine particles of carbon, has recently been proposed as a low-cost 
alternative to expensive carbon materials, such as graphene, in the field of electrochemistry showing great performance as an electric conductive agent (Lounasvuori et al., 2018).

Parabens are synthetic chemicals used as preservatives in a wide variety of products, like pharmaceuticals, cosmetics and food. Parabens are excreted through urine as 4-hydroxybenzoic acid (Fransway et al., 2019b), and are considered contaminants of emerging concern (Frontistis et al., 2017). In medications, they are recommended at concentrations of no more than $0.1 \%$, and they are allowed as preservatives in cosmetics at concentrations up to $0.4 \%$ when used alone (in the United States). The acceptable daily intake (ADI) has been calculated to be $10 \mathrm{mg} / \mathrm{kg}$ of body weight (Fransway et al., 2019a, 2019b; Reeder and Atwater, 2019; Liao et al., 2013).

Concerns exist regarding the endocrine discruption or carcinogenicity associated with parabens. However, it should be noted that controversial results have been reported for their health effects (Reeder and Atwater, 2019; Haman et al., 2015). Since parabens are ubiquitous in environmental matrices worldwide, efficient treatment processes must be employed for their elimination and to avert their accumulation (Haman et al., 2015).

Few articles exist on parabens treatment by advanced oxidation processes, and specifically by electrochemical methods (Gomes et al., 2016), and even less dealing with BDD oxidation (Frontistis et al., 2017; Dominguez et al., 2016; Steter et al., 2014a; 2014b). It should be noted that the studies of Steter et al. $(2014 \mathrm{a} ; 2014 \mathrm{~b})$ focus on the elimination and mineralization of an unrealistically high concentration of methyl paraben for environmental samples (100 mg/L). Much lower parabens concentrations (in the range of $\mu \mathrm{g} / \mathrm{L}$ ) have been measured in influent of domestic wastewater treatment plants (WTP) (Giger et al., 2009). Dominguez et al. (2016) examined parabens decomposition efficiency by BDD oxidation in aqueous matrices and found that the initial concentration was the most important factor. Notably, an increase of the initial paraben concentration caused a decrease of the efficiency of their removal. Interestingly, a synergistic effect on the efficiency of removal has been recorded in surface water (river). This finding was attributed to the probable presence of chloride ions, the resulting rise of solution conductivity and the formation of additional secondary oxidant species that diffuse in the bulk solution (Dominguez et al., 2016).

In one of our previous studies (Frontistis et al., 2017) regarding the BDD mediated oxidation of ethyl paraben at environmentally rational concentration (at the $\mu \mathrm{g} / \mathrm{L}$ concentration level), we found that the removal rate followed a pseudo-first order kinetic expression concerning paraben concentration and depended on the type of supporting electrolyte, the current density, and the complexity of the water matrix. In the context of the same study, reaction mechanisms were postulated by identifying major transformation by-products and elucidating reaction pathways with different electrolytes. 
In the present study, we further focused on the water matrix effect on the BDD anodic oxidation for the degradation of BP at a concentration level of $0.5 \mathrm{mg} / \mathrm{L}$, by studying various water matrices, including bottled water, secondary effluent, surface water, ultrapure water and ultrapure water spiked with humic acid. Moreover, anodic oxidation was compared to SR-AOP concerning process efficiency in actual matrices to highlight how possible interferences amongst target and non-target water constituents may dictate treatment performance.

\section{Experimental and analytical}

2.1. Chemicals

Butyl paraben (BP) $\left(\mathrm{HO}-\mathrm{C}_{6} \mathrm{H}_{4}-\mathrm{CO}-\mathrm{O}-\left(\mathrm{CH}_{2}\right)_{3}-\mathrm{CH}_{3}, \mathrm{CAS}\right.$ no: 94-26-8) was provided by SigmaAldrich. Solutions were prepared by using ultrapure water (UW, $\mathrm{pH}=6.5$ ) which was derived from a Millipore Milli-Q Gradient A10 system. To test the effect of matrix, various actual water matrices, including WW, BW, SW, UW, and UW spiked with HA were used. For experiments with BW, a commercially available natural mineral water was used. WW was sampled from the WTP of the University of Patras, while SW was collected from the region of Attica, Greece (TOC $=2.7 \mathrm{mg} / \mathrm{L}$, $\mathrm{pH}=7.5$ ). More details on BW, WW and SW characteristics are given elsewhere (Frontistis et al., 2017; Tsiampalis et al., 2019). Technical grade humic acid (HA, CAS no: 1415-93-6) was supplied from Sigma-Aldrich. Sulfuric acid or sodium hydroxide used for $\mathrm{pH}$ adjustment, sodium chloride, sodium sulfate, sodium bircabonate, sodium persulfate (SPS: $\mathrm{Na}_{2} \mathrm{~S}_{2} \mathrm{O}_{8}$ ), methanol and t-butanol were purchased from Sigma-Alrdich. Carbon black (CB: Vulcan XC72R) was supplied by Cabot.

\subsection{Reactor setup and experimental procedure}

The experimental set up of the electrochemical reactor consised of two electrodes (a boron doped diamond electrode served as the anode and a 304 stainless steel electrode served as the cathode, both with a surface area of $8 \mathrm{~cm}^{2}$ ). More information can be found in other studies of our group (Kouskouki et al., 2018; Frontistis et al., 2017). In specific expirements, stainless steel and platimum with a surface area of $8 \mathrm{~cm}^{2}$ were also used as anode to examine the effect of the anodic material.

In order to evaluate the influence of operating conditions on BP removal, experiments were conducted at 1.4-143 mA/cm ${ }^{2}$ current density, $0.1 \mathrm{M}$ electrolyte concentration and 250-2000 $\mu \mathrm{g} / \mathrm{L}$ $\mathrm{BP}$ concentration. Experiments were performed at their inherent $\mathrm{pH}$, except of the experiments that were conducted at acidic or alkaline conditions with the addition of the appropriate volume of $\mathrm{H}_{2} \mathrm{SO}_{4}$ or $\mathrm{NaOH}$.

For SR-AOP experiments, a pyrex vessel of $250 \mathrm{~mL}$ capacity open to the atmosphere was employed. In a typical run, $120 \mathrm{~mL}$ of an aqueous solution containing $0.5 \mathrm{mg} / \mathrm{L} \mathrm{BP}$ was loaded in 
139

140

141

142

143

144

145

146

the vessel followed by the addition of CB and SPS. The solution was under continuous magnetic stirring.

From either reacor, samples of $1.2 \mathrm{~mL}$ were collected at specific times, filtered with a $0.22 \mu \mathrm{m}$ syringe filter (PVDF) and then measured as follows.

\subsection{Determination of BP}

High performance liquid chromatography (Waters Alliance 2695) interfaced with a photodiode array detector (Waters 2996) was used for the detection of BP. Separation was achieved on a Kinetex XB-C18 100A column $(2.6 \mu \mathrm{m}, 2.1 \mathrm{~mm}$ x $150 \mathrm{~mm})$ and a $0.5 \mu \mathrm{m}$ inline filter (KrudKatcher Ultra) both purchased from Phenomenex. The mobile phase, consisting of 50:50 UW:acetonitrile, eluted isocratically at $0.25 \mathrm{~mL} / \mathrm{min}$ and $45^{\circ} \mathrm{C}$, while the injection volume was $100 \mu \mathrm{L}$.

\section{Results and discussion}

\subsection{Effect of operating conditions on degradation}

\subsubsection{Effect of the anodic material}

Wide variations exist between different electrode materials as it concerns their efficiency to oxidize water to ${ }^{\bullet} \mathrm{OH}$ or $\mathrm{O}_{2}$, and the nature of adsorbed radicals/electrode surface interaction.

In the present study, preliminary experiments were performed to investigate the effect of anodic material (BDD, stainless steel, platinum) on the degradation of $0.5 \mathrm{mg} / \mathrm{L} \mathrm{BP}$ at $50 \mathrm{~mA} / \mathrm{cm}^{2}$ current density with $0.1 \mathrm{M} \mathrm{Na}_{2} \mathrm{SO}_{4}$ in UW and the results are presented in Figure 1 . As can be seen, complete destruction of $\mathrm{BP}$ was achieved in 15 min of treatment with BDD anode, while the removal was about $40 \%$ and $18 \%$ for steel or platinum anode, respectively. BP removal was solely due to electrochemical processes and not just adsorption on the BDD surface as preliminary equilibration experiments had shown.

The results are in agreement with the work of Kouskouki et al. (2019), who observed complete removal of $245 \mu \mathrm{g} / \mathrm{L}$ piroxicam at $26.7 \mathrm{~mA} / \mathrm{cm}^{2}$ on BDD after $15 \mathrm{~min}$ of electrooxidation, while only $15 \%$ removal occurred in the presence of platinum.

The better efficiency of BDD anodic material compared to that of steel or platinum, may be attributed to the larger production of ${ }^{\circ} \mathrm{OH}$ on its surface. BDD is classified as "non-active" electrode, thus the surface of the BDD has only a physical interaction with ${ }^{\circ} \mathrm{OH}$ and, consequently, a greater production of hydroxyl radicals without forming higher oxides (Murugananthan et al., 2008). Likewise, a much better efficiency of BDD in comparison to $\mathrm{RuO}_{2}$, glassy carbon, $\mathrm{Pt}$, and $\mathrm{PbO}_{2}$, anodes has been described by Burgos-Castillo et al. (2018) and Murugananthan et al. (2008). Frontistis et al. (2018) reported that BDD was found to be more effective than platinum, since ampicillin abatement after 10 min of electrolysis was $39 \%$ and $68 \%$ for platinum and BDD, 
respectively. Similarly, BDD was found to have a significantly higher efficiency compared to platinum for the EO and mineralization of salicylic acid (Guinea et al., 2008). In the study of Barazesh et al. (2016), degradation rates normalized per surface area of BDD anode were several times (i.e. 100-2500\%) greater than in $\mathrm{Ti}-\mathrm{IrO}_{2}$.

BDD is considered as an ideal anodic material due to outstanding chemical, physical and electrochemical properties compared to other conventional electrode materials. The results of the present study confirm this finding, further supporting the technology of EO over BDD anodes which holds great promise to provide efficient wastewater treatment solutions.

\subsubsection{Effect of applied current}

Since electrons represent the energy input of the system, the role of the applied current is vital. The increase in current density favors the formation of ${ }^{\circ} \mathrm{OH}$, which in turn may maximize the mineralization of organic pollutants. Figure 2 shows the effect of applied current density on 0.5 $\mathrm{mg} / \mathrm{L}$ BP degradation in UW with $0.1 \mathrm{M} \mathrm{Na}_{2} \mathrm{SO}_{4}$. As seen in Figure 2A, which shows concentration-time profiles, an increase in current density results in increased conversion. Complete oxidation of BP can be accomplished within $5 \mathrm{~min}$ at $107-143 \mathrm{~mA} / \mathrm{cm}^{2}, 10 \mathrm{~min}$ at $71 \mathrm{~mA} / \mathrm{cm}^{2}$, and $15 \mathrm{~min}$ at $50 \mathrm{~mA} / \mathrm{cm}^{2}$. Figure 2B shows the effect of current density on the apparent rate constant, $\mathrm{k}_{\mathrm{app}}$, assuming that the electrochemical decomposition of BP follows pseudo-first order kinetics. Apparent rate constants are calculated from the slope of the straight lines associated with the plot of the logarithm of normalized concentrations over time (plots are not shown for brevity). Frontistis et al. (2018) showed that the rate of the degradation of antibiotic ampicillin remarkably increased by increasing current density. Similarly, a three-fold increase in the oxidation rate of ethyl paraben over BDD was recorded when the current augmented from 10 to $70 \mathrm{~mA} / \mathrm{cm}^{2}$ (Frontistis et al., 2017). Dominguez et al. (2016) showed that current density affected BDD oxidation of parabens in a statistically significant manner, in both UW and river water; in other studies (Dominguez et al., 2010), the influence of current on carbamazepine degradation over BDD was found to be the single most important variable followed by the concentration of salt and the flow rate. Abdelhay et al. (2017) showed that increasing applied current density positively affected the removal of color, COD, and turbidity of slaughterhouse wastewater. In the study of Deligiorgis et al. (2008), on BDD electrolysis of table olive processing wastewater, a statistically significant effect of the current, the initial COD, and the contact time on the degradation of phenols and COD was recorded. In another study, Murugananthan et al. (2008) found that bisphenol A (BPA) oxidation was a currentcontrolled process and occurred faster at greater current densities. In the study of Kenova et al. (2018), the decolorization of Mordant Blue 13 dye followed exponential decay with $k_{\text {app }}$ increasing with increasing applied current density. According to the authors, a remarkable increase in the dye 
removal rate at higher current density was due to the formation of additional radicals and other oxidizing species, (e.g. sulfate radicals, peroxodisulfate anions, $\mathrm{H}_{2} \mathrm{O}_{2}$ ). The removal of COD was increased with specific charge. However, the variation of current density had almost no effect on COD removal. This finding suggests the crucial role of mediated oxidation in the electrochemical oxidation. Interestingly, the work of Anglada et al. (2011) on the BDD electrolysis of landfill leachate showed that no statistically significant effect of the applied current on the removal of the pollutants was noted, under the studied conditions.

\subsubsection{Effect of BP concentration}

Figure 3 shows the influence of BP concentration on its degradation at $50 \mathrm{~mA} / \mathrm{cm}^{2}$ current density in UW with $0.1 \mathrm{M} \mathrm{Na}_{2} \mathrm{SO}_{4}$. Increasing initial concentration decreases the rate, which implies that the concentration of oxidants generated during the process is a limiting factor for the decomposition of organics. In fact, the rate that the oxidants are produced is expected to be nearly constant at fixed operating conditions, i.e. current density and the electrolyte used. Thus, the rate BP is degraded is a function of its concentration relative to the oxidants available for reaction and it decreases at higher BP concentrations. It should be noted here that although degradation data can still be fitted adequately to a pseudo-first order kinetic model from which $\mathrm{k}_{\text {app }}$ values are computed (shown next to the respective profiles in Figure 3), it is clear that the reaction is not true first order since rate constants change with initial BP concentration. In fact, this behavior implies a transition of rate order in regards to BP from first to zeroth.

Dominguez et al. (2016) showed that the initial parabens concentration was the unique most influential factor for their electrochemical removal in ultrapure water and river water; an increase in the organics concentration resulted in a decline in the efficiency. Frontistis et al. (2018) found that nearly complete degradation of ampicillin could be reached after $20 \mathrm{~min}$ of treatment, independently of the initial concentration in the range $0.8-3 \mathrm{mg} / \mathrm{L}$. Moreover, the percent removal was higher for lower concentration of ampicillin. This finding indicates that ampicillin removal did not follow true first order kinetics with regards to the concentration of ampicillin. In another study of Murugananthan et al. (2008), it was shown that BPA conentration could affect its mineralization, especially at the early stages of the reaction. An increase of the mineralization current efficiency (which is a measure of energy consumption) was recorded with increasing pollutant concentration, and decreasing current density (Murugananthan et al., 2008).

\subsubsection{Effect of water matrices}

Since electrochemical oxidation aims at treating real wastewater, the efficiency of the method in real aqueous matrices and not only in synthetic wastes is of particular interest. Figure 4A shows the 
effect of various actual water matrices, including WW containing ca $10 \mathrm{mg} / \mathrm{L}$ organic carbon and inorganics, BW containing mainly ca $250 \mathrm{mg} / \mathrm{L}$ bicarbonate, SW, UW, and UW spiked with 10 $\mathrm{mg} / \mathrm{L}$ HA (i.e. to simulate the natural organic matter of waters), on the degradation of $0.5 \mathrm{mg} / \mathrm{L} \mathrm{BP}$ at $50 \mathrm{~mA} / \mathrm{cm}^{2}$ current density with $0.1 \mathrm{M} \mathrm{Na}_{2} \mathrm{SO}_{4}$. Interestingly, matrix complexity seems to favor $\mathrm{BP}$ degradation, i.e. the rate decreases in the order $\mathrm{WW} \sim \mathrm{BW}>\mathrm{SW}>\mathrm{UW}$, thus implying some kind of synergy between the organic and/or inorganic water matrix constituents, ROS and the anode surface. The findings of the present study are in agreement with previous studies of our group (Frontistis et al., 2017), where the researchers examined the BDD electrooxidation of $200 \mu \mathrm{g} / \mathrm{L}$ ethyl paraben in $0.1 \mathrm{M} \mathrm{Na}_{2} \mathrm{SO}_{4}$. The promotion of oxidation reactions in the bulk solution as a result of the indirect formation of reactive oxygen species, produced by the presence of different inorganic ions like $\mathrm{SO}_{4}{ }^{2}, \mathrm{Cl}^{-}$, etc, may be the reason behind this finding (Katsaounis and Souentie, 2013; Velegraki et al., 2010).

Indeed, Dominguez et al. (2016), in their study on parabens BDD oxidation, observed a great synergistic effect on the oxidation efficiency in the river water matrix, possibly due to the presence of chloride ions at high concentration $(40.4 \mathrm{mg} / \mathrm{L})$, which augments the solution conductivity and favors the formation of secondary oxidants such as $\mathrm{HClO} / \mathrm{ClO}^{-}$or chlorine.

Regarding the presence of HA, it is well known that HA negatively affects the oxidation process by competing with BP for reactive species and electrode surface sites, leading to reduced degradation rates (Frontistis et al., 2018; Fernandes et al., 2016b). For example, Woisetschläger et al. (2013) noted that glucose degradation became progressively inhibited by increasing the amount of HA. Similarly, in the study of Frontistis et al. (2018) on the BDD electrochemical destruction of antibiotic ampicillin, the presence of $10 \mathrm{mg} / \mathrm{L}$ of HA led to a decrease in the observed kinetic constant by $40 \%$. It must be noted here that although HA is typically selected as an analogue of the natural organic matter in water matrices, the effluent organic matter in WW may also contain other species such as soluble microbial products and traces of non-biodegradable pollutants. In this view, the use of HA may not be fully representative of the organic content in WW matrices.

Figures $4 \mathrm{~B}$ and $4 \mathrm{C}$ show the effect of the addition of $\mathrm{NaCl}$ and $\mathrm{NaHCO}_{3}$, respectively, while Figure 4D shows the effect of the addition of sodium persulfate (SPS) in UW which is a mild oxidant (redox potential of $2.1 \mathrm{~V}$ ) and has the ability to oxidize organic pollutants (Ioannidi et. al., 2018). Furthermore, SPS activation causes the production of sulfate radicals with a redox potential of (2.53.1) $\mathrm{V}$, according to reaction (1), which can be used for the elimination of organic pollutants (Matzek and Carter, 2016; Ghanbari et al., 2017).

$\mathrm{S}_{2} \mathrm{O}_{8}^{2-}+e^{-} \rightarrow 2 \mathrm{SO}_{4}^{2-}+\mathrm{SO}_{4}^{-\bullet}$ 
The presence of bicarbonate anion slightly slows down the rate of oxidation of BP (Figure 4C) possibly as a result of the fact that the bicarbonate anion scavenges hydroxyl radicals (Wu and Linden, 2010). In contrast, the addition of chloride (Figure 4B) favors the reaction presumably due to the formation of chlorine-based oxidative species, including chlorohydroxyl radicals according to reactions (2-7). In bibliography, the positive effect of $\mathrm{Cl}^{-}$has often been underlined (GarciaEspinoza et al., 2018; Frontistis et al., 2017; Katsaounis and Souentie, 2013). Garcia-Espinoza et al. (2018), focused on the effect of electrocatalytically generated active chlorine on carbamazepine destruction.

$2 \mathrm{Cl}^{-} \rightarrow \mathrm{Cl}_{2}+2 e^{-}$

$\mathrm{Cl}^{-} \rightarrow \mathrm{Cl}^{\bullet}+e^{-}$

$\mathrm{Cl}^{\bullet}+\mathrm{Cl}^{\bullet} \rightarrow \mathrm{Cl}_{2}$

$\mathrm{Cl}^{\bullet}+\mathrm{O}_{2} \rightarrow \mathrm{ClO}_{2}$

$\mathrm{Cl}_{2}+\mathrm{H}_{2} \mathrm{O} \rightarrow \mathrm{HClO}+\mathrm{Cl}^{-}+\mathrm{H}^{+}$

$\mathrm{HClO} \stackrel{\rightarrow}{\leftarrow} \mathrm{ClO}^{-}+\mathrm{H}^{+}$

Similar results with the present study were reported by Lebik- Elhadi et al. (2018). They investigated the BDD anode oxidation of thiamethoxam with $0.1 \mathrm{M} \mathrm{Na}_{2} \mathrm{SO}_{4}$ and mentioned that the addition of $\mathrm{NaCl}$ at concentrations reaching $100 \mathrm{mg} / \mathrm{L}$ increased degradation. They also reported that the $\mathrm{k}_{\text {app }}$ was $0.72 \mathrm{~min}^{-1}$ at $100 \mathrm{mg} / \mathrm{L} \mathrm{NaCl}$ and $0.22 \mathrm{~min}^{-1}$ without $\mathrm{NaCl}$. A similarly positive but less pronounced effect was recorded for the addition of 100 and $200 \mathrm{mg} / \mathrm{L}$ sodium persulfate (Figure 4D). This behavior can be attirbuted to the electrochemical activation of persulafte for the generation of selective sulfate radicals (Frontistis et al., 2018; Chen et al., 2018).

Candia-Onfray et al. (2018) showed recently that high concentrations of sulfate and chloride support the production of oxidants (e.g. active chlorine species, hydroxyl radicals) that can eventually oxidize the organic loading of winery wastewater in the bulk solution. In the work of Oliveira et al. (2018) focusing on the electrooxidation of industrial phenolic wastewaters, it was shown that the presence of chloride in the wastewater favored the electrogeneration of strong oxidant species, (mainly hypochlorous acid, but also chlorine, and hypochlorite) and increased the efficiency of the process. The effect of the presence of chloride ion on the oxidation process of various synthetic samples was also studied by Fernandes et al. (2016a), who reported that the presence of chlorides enhanced the removal of organic matter and nitrogen. The same research group (Fernandes et al., 2016b) studied the EO of HA and sanitary landfill leachate samples. It was 
312

shown that the conversion of organics and nitrogen increased with the chloride ion concentration, and the applied current density.

However, it should be noted that although electrochemical degradation is usually enhanced by chloride ions, this is unfortunately accompanied by the formation of undesired organochlorinated by-products. These products alongside with residual chlorine may both be incriminated for elevated post-treatment ecotoxicity (Garcia-Segura et al., 2015; Katsoni et al., 2014; Boudreau et al., 2010). Barazesh et al. (2016) showed that transformation rates for the vast majority of the contaminants in industrial wastewater increased with chlorides, but high concentrations of $\mathrm{HCO}_{3}{ }^{-}$frequently altered transformation rates because of the creation of selective oxidants. Electron-poor contaminants were found to have a decreased reactivity, while compounds with phenolic and amine moieties were characterized by increased reactivity. In the same study, it was found that the addition of $10 \mathrm{mM}$ $\mathrm{HCO}_{3}{ }^{-}$declined the degradation of different pollutants by $50 \%$ to $75 \%$ relative to the conversion in $10 \mathrm{mM} \mathrm{NaCl}$ (Barazesh et al., 2016).

Treatment performance may also be affected by effluent pH (Tsantaki et al., 2012), whose effect hinges on the nature of the implicated organics. Since the various matrices have different $\mathrm{pH}$ values (between 6 and 8), experiments were performed in UW at initial $\mathrm{pH}$ values between 3 and 8 . Interestingly, Figure $4 \mathrm{E}$ shows no $\mathrm{pH}$ effect on degradation of $0.5 \mathrm{mg} / \mathrm{L} \mathrm{BP}$. In all cases complete degradation can be reached within $15 \mathrm{~min}$. Similar results about the slight influence of initial $\mathrm{pH}$ on the oxidation of organic micropollutants using BDD oxidation were reported by Frontistis et. al. (2017), Pereira et al. (2012) and El-Ghenymy et al. (2012). However, other studies reported contradictory results concerning the pH effect on the BDD EO (Siedlecka et al., 2018; Abdelhay et al., 2017; Garcia-Segura et al., 2015). pH was found to have a remarkable role on the removal rate of BPA, which was favored at pH 10 (Murugananthan et al., 2008). Moreover, the electrochemical abatement of sulfonamides was strongly affected by $\mathrm{pH}$, alongside other operating conditions such as temperature and inorganic ions (Fabianska et al., 2014).

Finally, representative experiments were performed in the presence of $1000 \mathrm{mg} / \mathrm{L} \mathrm{t}$-butanol, whose affinity for hydroxyl radicals is well-documented ( $\mathrm{Li}$ et al., 2013). The results are shown in Figure 4F in terms of apparent rate constants in the absence (black bars) and in the presence (dashed bars) of alcohol. It must be noted here that the latter values have been multiplied 100 times to allow for clarity. Evidently, the reaction is nearly completely quenched in the presence of alcohol irrespective of the water matrix, thus implying that hydroxyl radicals are the dominant oxidizing species.

\subsubsection{Effect of low current in various water matrices}

One of the major disadvantages of electrolysis is the need for large amounts of energy. For this reason, the performance of the process in different aqueous matrices was studied at a lower current 
density.

The effect of low current density $\left(1.4 \mathrm{~mA} / \mathrm{cm}^{2}\right)$ on $0.5 \mathrm{mg} / \mathrm{L} \mathrm{BP}$ concentration with $0.1 \mathrm{M} \mathrm{Na}_{2} \mathrm{SO}_{4}$ and various matrices (WW, WW without the addition of electrolyte, BW, UW and $200 \mathrm{mg} / \mathrm{L} \mathrm{NaCl}$ in $\mathrm{UW}$ ) is shown in Figure 5; the rate decreases in the order $\mathrm{UW}$ with $\mathrm{NaCl}>\mathrm{WW}$ without salt $>\mathrm{WW}>\mathrm{BW}>\mathrm{UW}$. Concerning WW, BW and UW, it is noticed that the degradation follows the same trend as in Figure 4A, but the time needed for the removal of BP is increased. For WW, the time required for BP removal was augmented from $3 \mathrm{~min}$ at $50 \mathrm{~mA} / \mathrm{cm}^{2}$ to more than $15 \mathrm{~min}$ at 1.4 $\mathrm{mA} / \mathrm{cm}^{2}$. The addition of $0.1 \mathrm{M} \mathrm{Na}_{2} \mathrm{SO}_{4}$ slightly decreased the degradation rate in WW, as can be seen in Figure 5. It should be emphasized that the decreased current density does not significantly affect the conversion of BP since it becomes $100 \%$ and $90 \%$ in $5 \mathrm{~min}$ at $50 \mathrm{~mA} / \mathrm{cm}^{2}$ and 1.4 $\mathrm{mA} / \mathrm{cm}^{2}$, respectively. This result confirms the significance of chloride during BDD anodic oxidation as it leads to the formation of active chlorine species (Zhang et al., 2016).

Contrarily, the degradation rate of BP in BW and UW was suspended. A possible explanation for this result is the strong dependence between current density and the generation of hydroxyl radicals that are the principal oxidizing species in the absence of chlorides. As already mentioned, the formation of hydroxyl radicals is favored by the augmentation of current density, which in turn may maximize the mineralization of organic pollutants.

\subsubsection{Comparison with $S R$-AOPs}

As already demonstrated in Figure 4D, the presence of SPS can promote the electrochemical oxidation of BP due to the formation of sulfate radicals. Since SR-AOPs have recently gained attention in water treatment, we decided to compare the EO of BP with that of persulfate oxidation activated by carbocatalysis, as follows (Dimitriadou et al., 2019):

$$
\begin{aligned}
& 2 \mathrm{~S}_{2} \mathrm{O}_{8}{ }^{2-} \stackrel{\mathrm{CB}}{\longrightarrow} \mathrm{S}_{2} \mathrm{O}_{8}^{\cdot-}+\mathrm{SO}_{4}^{2-}+\mathrm{SO}_{4}^{\cdot-} \\
& \mathrm{SO}_{4}^{\cdot-}+\mathrm{H}_{2} \mathrm{O} \rightarrow \mathrm{SO}_{4}^{2-}+\cdot \mathrm{OH}+H^{+}
\end{aligned}
$$

The concentration levels of the oxidant and the activator are critical for the efficient degradation of $\mathrm{BP}$, as this is demonstrated in Figure 6. The degradation rate increases with increasing either SPS or $\mathrm{CB}$ concentration within the concentration ranges tested, however the maximum rate recorded in either case (Figure 6B and 6D) is lower than that of EO at current densities $\geq 50 \mathrm{~mA} / \mathrm{cm}^{2}$ (Figure 2B). It is also noted that $\mathrm{CB}$ behaves as adsorbent since about 35\% BP removal occurs after 45 min in the absence of SPS (Figure 6A); this is consistent with its considerable specific surface area of $216 \mathrm{~m}^{2} / \mathrm{g}$ (Dimitriadou et al., 2019). On the other hand, SPS itself is a mild oxidant as 30\% degradation occurs after $45 \mathrm{~min}$ without activator (Figure 6C). 
The performance of the SR-AOP in actual matrices is demonstrated in Figure 7A; unlike what happens in EO, degradation efficiency decreases with matrix complexity, i.e. UW>BW>WW. This also is consistent with the negative impact of bicarbonate (Figure 7B) and chloride (Figure 7D) on BP degradation. Bicarbonate may scavenge the highly active sulfate and/or hydroxyl radicals producing the less reactive carbonate radicals $\left(\mathrm{HCO}_{3}^{\circ}\right)$ (Ma et al., 2018). On the other hand, sulfate radicals may react with chloride (Lutze et al., 2015) to form other less reactive radicals such as chlorine and dichloride radicals $\left(\mathrm{Cl}^{\circ}, \mathrm{Cl}_{2}^{*}\right)$ (Metheniti et al., 2018), thus lowering degradation rates. Noticeably, the effect of HA on degradation was found to be commonly detrimental for both EO (Figure 4A) and SR-AOP (Figure 7C); in the latter case, HA may occupy active sites of the CB surface, thus limiting availability for SPS and/or BP.

To evaluate indirectly the relative contribution of sulfate and hydroxyl radicals to BP degradation, experiments were conducted with methanol and t-butanol as radical scavengers and the results, in terms of apparent rate constants, are summarized in Figures 7E and 7F, respectively. Noticeably, methanol inhibits considerably BP degradation and this is more pronounced at $1000 \mathrm{mg} / \mathrm{L}$ concentration, however, this seems not to be the case with t-butanol. Given that butanol has a 6-fold greater affinity for hydroxyl radicals than methanol (Li et al., 2013), it can be hypothesized that sulfate radicals play a key role in degrading BP.

\section{Conclusions}

This work demonstrates the efficient application of BDD anodic oxidation for the destruction of butyl paraben, a representative endocrine disrupting compound of the parabens family, in environmentally relevant matrices and levels. The process is expectedly favored (i) at increased current densities, where the rate of ROS production is accelerated, and (ii) in the presence (intrinsic or deliberate) of ions such as chloride that can electrochemically generate additional chlorine-based oxidative species. As a matter of fact, there appears to be a reaction rate trade-off between high current densities and chlorine-free electrolytes and vice versa. What is less expected is the fact that matrix complexity seems to favor paraben degradation. This finding underlines the existence of some kind of synergy between the organic and/or inorganic water matrix constituents, ROS and the anode surface. This positive interplay, however, seems to be process-specific as has been demonstrated through the application of an SR-AOP, where persulfate was carbocatalytically activated and the resulting sulfate radicals could degrade butyl paraben; in this case, matrix complexity was detrimental to degradation.

Nowadays, an issue of great concern is the design of advanced technologies for the removal or persistent pollutants from different water matrices. The obtained results showed the water matrix 
effect on the degradation of BP and underlined the need for further work on the in-depth examination of the EO of organic compounds and the application of this technology in real life systems.

\section{References}

Abdelhay, A., Jum'h, I., Abdulhay, E., Al-Kazwini, A., Alzubi, M., 2017. Anodic oxidation of slaughterhouse wastewater on boron-doped diamond: process variables effect. Water Sci. Technol. 76(11-12), 3227-3235.

Abid, M.F., Alwan, G.M., Abdul-Ridha, L.A., 2016. Study on catalytic wet air oxidation process for phenol degradation in synthetic wastewater using trickle bed reactor. Arab. J. Sci. Eng. 41(7), 2659-2670.

Anglada, A., Urtiaga, A., Ortiz, I., Mantzavinos, D., Diamadopoulos, E., 2011. Boron-doped diamond anodic treatment of landfill leachate: evaluation of operating variables and formation of oxidation by-products. Water Res. 45(2), 828-838.

Barazesh, J.M., Prasse, C., Sedlak, D.L., 2016. Electrochemical transformation of trace organic contaminants in the presence of halide and carbonate ions. Environ. Sci. Technol. 50(18), 10143 10152.

Boudreau, J., Bejan, D., Li, S., Bunce, N.J., 2010. Competition between electrochemicaladvanced oxidation and electrochemical hypochlorination of sulfametho-xazole at a boron-doped diamond anode. Ind. Eng. Chem. Res. 49, 2537-2542.

Burgos-Castillo, R.C., Sires, I., Sillanpaa, M., Brillas, E., 2018. Application of electrochemical advanced oxidation to bisphenol A degradation in water. Effect of sulfate and chloride ions. Chemosphere 194, 812-820.

Candia-Onfray, C., Espinoza, N., Sabino da Silva, E.B., Toledo-Neira, C., Espinoza, L.C., Santander, R., García, V., Salazar, R., 2018. Treatment of winery wastewater by anodic oxidation using BDD electrode. Chemosphere 206, 709-717.

Chen, L., Lei, C., Li, Z., Yang, B., Zhang, X., Lei, L., 2018. Electrochemical activation of sulfate by BDD anode in basic medium for efficient removal of organic pollutants. Chemosphere 210, 516523.

Deligiorgis, A., Xekoukoulotakis, N.P., Diamadopoulos, E., Mantzavinos, D., 2008.

Electrochemical oxidation of table olive processing wastewater over boron-doped diamond electrodes: Treatment optimization by factorial design. Water Res. 42, 1229-1237.

Dimitriadou, S., Frontistis, Z., Petala, A., Bampos, G., Mantzavinos, D., 2019. Carbocatalytic activation of persulfate for the removal of drug diclofenac from aqueous matrices Catal. Tod., in press

Domínguez, J.R., González T., Palo, P., Sánchez-Martín, J., 2010. Electrochemical advanced oxidation of carbamazepine on boron-doped diamond anodes. Influence of operating variables. Ind. Eng. Chem. Res. 49, 8353-8359. 
462

463

464

465

466

467

468

469

470

471

472

473

474

475

476

477

478

479

480

481

482

483

484

485

486

487

488

489

490

491

492

493

494

495

496

497

498

499

500

501

502

503

504

505

506

507

508

509

510

511

512

Domínguez, J.R., Muñoz-Peña, M.J., González, T., Palo, P., Cuerda-Correa, E.M., 2016. Parabens abatement from surface waters by electrochemical advanced oxidation with boron doped diamond anodes. Environ. Sci. Pollut. Res. Int. 23(20), 20315-20330.

El-Ghenymy, A., Arias, C., Cabot, P.L., Centellas, F., Garrido, J.A., Rodriguez, R.M.,

Brillas, E., 2012. Electrochemical incineration of sulfanilic acid at a boron-doped diamond anode. Chemosphere 87, 1126-1133.

Fabiańska, A., Białk-Bielińska, A., Stepnowski, P., Stolte, S., Siedlecka, E.M., 2014. Electrochemical degradation of sulfonamides at BDD electrode: kinetics, reaction pathway and ecotoxicity evaluation. J. Hazard. Mater. 280, 579-587.

Fernandes, A., Coelho, J., Ciríaco, L., Pacheco, M.J., Lopes, A., 2016a. Electrochemical wastewater treatment: influence of the type of carbon and of nitrogen on the organic load removal. Environ. Sci. Pollut. Res. Int. 23(24), 24614-24623.

Fernandes, A., Santos, D., Pacheco, M.J., Ciríaco, L., Lopes, A., $2016 b$. Electrochemical oxidation of humic acid and sanitary landfill leachate: Influence of anode material, chloride concentration and current density. Sci. Total Environ. 541, 282-291.

Fransway, A.F., Fransway, P.J., Belsito, D.V., Warshaw, E.M., Sasseville, D., Fowler, J.F. Jr., DeKoven, J.G., Pratt, M.D., Maibach, H.I., Taylor, J.S., Marks, J.G., Mathias, C.G.T., DeLeo, V.A., Zirwas, J.M., Zug, K.A., Atwater, A.R., Silverberg, J., Reeder, M.J., 2019a. Parabens. Dermatitis 30, 3-31.

Fransway, A.F., Fransway, P.J., Belsito, D.V., , Yiannias, J.A., 2019b. Paraben toxicology. Dermatitis 30, 32-45.

Frontistis, Z., Mantzavinos, D., 2017. Wastewater and Biosolids Management, IWA Publishing, 132.

Frontistis, Z., Mantzavinos, D., Meriç, S., 2018. Degradation of antibiotic ampicillin on borondoped diamond anode using the combined electrochemical oxidation - Sodium persulfate process. J. Environ. Manage. 223, 878-887.

Frontistis, Z., Antonopoulou, M., Yazirdagi, M., Kilinc, Z., Konstantinou, I., Katsaounis, A., Mantzavinos, D., $2017 . \quad$ Boron doped diamond electrooxidation of ethyl paraben: The effect of electrolyte on by-products distribution and mechanisms. J. Environ. Manage. 195(Pt 2), 148-156.

García-Espinoza, J.D., Mijaylova-Nacheva, P., Avilés-Flores, M, 2018. Electrochemical carbamazepine degradation: Effect of the generated active chlorine, transformation pathways and toxicity. Chemosphere 192, 142-151.

Garcia-Segura, S., Keller, J., Brillas, $\quad$ E., $\quad$ Radjenovic, $\quad$ J., 2015. Removal of organic contaminants from secondary effluent by anodic oxidation with a borondoped diamond anode as tertiary treatment. J. Hazard. Mater. 283, 551-557.

Ghanbari, F., Moradi M., 2017. Application of peroxymonosulfate and its activation methods for degradation of environmental organic pollutants: review, Chem. Eng. J. 310, 41-62. 
513

514

515

516

517

518

519

520

521

522

523

524

525

526

527

528

529

530

531

532

533

534

535

536

537

538

539

540

541

542

543

544

545

546

547

548

549

550

551

552

553

554

555

556

557

558

559

560

561

Giger, W., Gabriel, F., Jonkers, N., Wettstein, F., Kohler, H., 2009. Environmental fate of phenolic endocrine disruptors: field and laboratory studies. Philosophical Transactions of the Royal Society A: Mathematical. Phys. Eng. Sci. 367(1904), 3941-3963.

Gomes, F.E.R., de Souza, N.E., Galinaro, Carlos A., Arriveti, L.O.R., de Assis, J.B., TremiliosiFilho, G., 2016. Electrochemical degradation of butyl paraben on platinum and glassy carbon electrodes. J. Electroanal. Chem. 769, 124-130.

Guinea, E., Arias, C., Cabot, P.L., Garrido, J.A., Rodríguez, R.M., Centellas, F., Brillas, E., 2008. Mineralization of salicylic acid in acidic aqueous medium by electrochemical advanced oxidation processes using platinum and boron-doped diamond as anode and cathodically generated hydrogen peroxide. Water Res. 42, 499-511.

Haman, C., Dauchy, X., Rosin, C., Munoz, J.F., 2015. Occurrence, fate and behavior of parabens in aquatic environments: a review. Water Res. 68, 1-11.

Henke, A.H., Saunders, T.P., Pedersen, J.A., Hamers, R.J., 2019. Enhancing electrochemical efficiency of hydroxyl radical formation on diamond electrodes by functionalization with hydrophobic monolayers. Langmuir 35(6), 2153-2163.

Ioannidi, A., Frontistis, Z., Mantzavinos, D., 2018. Destruction of propyl paraben by persulfate activated with UV-A light emitting diodes. Journal of Environ. Chem. Eng. 6, 2992-2997.

Katsoni, A., Mantzavinos, D., Diamadopoulos, E., 2014. Coupling digestion in a pilot-scale UASB reactor and electrochemical oxidation over BDD anode to treat diluted cheese whey. Environ. Sci. Pollut. Res. Int. 21(21), 12170-12181.

Katsaounis, A., Souentie, S., 2013. In: Savinell, R.F., Ota, Ken-ichiro, Kreysa, G. (Eds.), In-cell Mediated (Via Active Chlorine) Electrochemical Oxidation of Organic.

Kenova, T.A., Kornienko, G.V., Golubtsova, O.A., Kornienko, V.L., Maksimov, N.G., 2018. Electrochemical degradation of Mordant Blue 13 azo dye using boron-doped diamond and dimensionally stable anodes: influence of experimental parameters and water matrix. Environ. Sci. Pollut. Res. Int. 25(30), 30425-30440.

Klavarioti, M., Mantzavinos, D., Kassinos, D., 2009. Removal of residual pharmaceuticals from aqueous systems by advanced oxidation processes. Environ. Int. 35(2), 402-417.

Kouskouki, A., Chatzisymeon, E., Mantzavinos, D., Frontistis, Z., 2019. Electrochemical Degradation of Piroxicam on a Boron-Doped Diamond Anode: Investigation of Operating Parameters and Ultrasound Synergy. ChemElectroChem 6, 841-847.

Kraft, A., Stadelmann, M., Blaschke, M., 2003. Anodic oxidation with doped diamond electrodes: a new advanced oxidation process. J. Hazard. Mater. 103(3), 247-261.

Lebik-Elhadi, H., Frontistis, Z., Ait-Amar, H., Amrani, S., Mantzavinos, D., 2018. Electrochemical oxidation of pesticide thiamethoxam on boron doped diamond anode: Role of operating parameters and matrix effect. Process Saf. Environ. 116, 535-541. 
Li, B., Li, L., Lin, K., Zhang, W., Lu, S., Luo, Q., 2013. Removal of 1,1,1-trichloroethane from aqueous solution by a sono-activated persulfate process. Ultrason. Sonochem. 20, 855-863.

Liao, C., Liu, F., Kannan, K., 2013. Occurrence of and dietary exposure to parabens in foodstuffs from the United States. Environ. Sci. Technol. 47, 3918-3925.

Lounasvuori, M.M., Kelly, D., Foord, J.S., 2018. Carbon black as low-cost alternative for electrochemical sensing of phenolic compounds. Carbon 129, 252-257.

Lutze, H.V., Kerlin, N., Schmidt, T.C., 2015. Sulfate radical-based water treatment in presence of chloride: Formation of chlorate, inter-conversion of sulfate radicals into hydroxyl radicals and influence of bicarbonate. Water Res. 72, 349-360.

Ma, J., Li, H., Yang, Y., Li, X., 2018. Influence of water matrix species on persulfate oxidation of phenol: reaction kinetics and formation of undesired degradation byproducts. Water Sci. Technol. $2017,340-350$.

Matzek, L.W., Carter, K. E., 2016. Activated persulfate for organic chemical degradation: a review. Chemosphere 151, 178-188.

Metheniti, M.E., Frontistis, Z., Ribeiro, R.S., Silva, A.M.T., Faria, J.L., Gomes, H.T., Mantzavinos, D., 2018. Degradation of propyl-paraben by activated persulfate using iron-containing magnetic carbon xerogels: investigation of water matrix and process synergy effects, Environ. Sci. Pollut. Res. 25, 34801-34810.

Murugananthan, $\quad$ M., Yoshihara, $\quad$ S., Rakuma, $\quad$ T., Shirakashi, $\quad$ T., 2008. Mineralization of bisphenol A (BPA) by anodic oxidation with borondoped diamond (BDD) electrode. J. Hazard. Mater. 154(1-3), 213-220.

Oliveira, E.M.S., Silva, F.R., Morais, C.C.O., Oliveira, T.M.B.F., Martínez-Huitle, C.A., Motheo, A.J., Albuquerque, C.C., Castro, S.S.L., 2018. Performance of (in)active anodic materials for the electrooxidation of phenolic wastewaters from cashew-nut processing industry. Chemosphere 201,740-748.

Pecková, K., Musilová, J., Barek, J., 2009. Boron-doped diamond film electrodes-new tool for voltammetric determination of organic substances. Crit. Rev. Anal. Chem. 39:3, 148-172.

Pereira, G.F., Rocha-Filho, R.C., Bocchi, N., Biaggio, S.R., 2012. Electrochemical degradation of bisphenol A using a flow reactor with a boron-doped diamond anode. Chem. Eng. J. 198-199, 282288.

Reeder, M., Atwater, A.R., 2019. Parabens: the 2019 nonallergen of the year. Cutis. 103(4), 192193.

Sarkka, H., Bhatnagar, A., Sillanpaa., M., 2015. Recent developments of electro-oxidation in water treatment - a review. J. Electroanal. Chem. 754, 46-56.

Siedlecka, E.M., Ofiarska, A., Borzyszkowska, A.F., Białk-Bielińska, A., Stepnowski, P., Pieczyńska, A., 2018. Cytostatic drug removal using electrochemical oxidation with BDD electrode: Degradation pathway and toxicity. Water Res. 144, 235-245. 
613
Steter, J.R., Rocha, R.S., Dionisio, D., Lanza, M.R.V., Motheo, A.J., 2014a. Electrochemical oxidation route of methyl paraben on a boron-doped diamond anode. Electrochim. Acta 117, 127133.

Steter, J.R., Dionisio, D., Lanza, M.R.V., Motheo, A.J., 2014b. Electrochemical and sonoelectrochemical processes applied to the degradation of the endocrine disruptor methyl paraben. J. Appl. Electrochem. 44, 1317-1325.

Tsantaki, $\quad$ E., Velegraki, $\quad$ T., Katsaounis, $\quad$ A., Mantzavinos, $\quad$ D., 2012. Anodic oxidation of textile dyehouse effluents on boron-doped diamond electrode. J. Hazard. Mater. 207-208, 91-6.

Tsiampalis, A., Frontistis, Z., Binas, V., Kiriakidis, G., Mantzavinos, D., 2019. Degradation of Sulfamethoxazole Using Iron-Doped Titania and Simulated Solar Radiation. Catalysts 9(7), 612

Velegraki, T., Balayiannis, G., Diamadopoulos, E., Katsaounis, A., Mantzavinos, D., 2010. Electrochemical oxidation of benzoic acid in water over boron-doped diamond electrodes: statistical analysis of key operating parameters, kinetic modeling, reaction by-products and ecotoxicity. Chem. Eng. J. 160, 538-548.

Woisetschläger, D., Humpl, B., Koncar, M., Siebenhofer, M., 2013. Electrochemical oxidation of wastewater - opportunities and drawbacks. Water Sci. Technol. 65, 1173-1179.

Wu, C., Linden, K.G., 2010. Phototransformation of selected organophosphorus pesticides: roles of hydroxyl and carbonate radicals. Water Res. 44, 3585-3594.

Zhang, C., Du, X., Zhang, Z., Fu, D., 2016. The peculiar roles of chloride electrolytes in BDD anode cells. RSC Advances 6, 65638-65643. 


\section{List of Figures}

Figure 1. Degradation of $0.5 \mathrm{mg} / \mathrm{L} \mathrm{BP}$ at $50 \mathrm{~mA} / \mathrm{cm}^{2}$ current density with $0.1 \mathrm{M} \mathrm{Na}_{2} \mathrm{SO}_{4}$ in $\mathrm{UW}$ as a function of anodic material.

Figure 2. Effect of current density (in $\mathrm{mA} / \mathrm{cm}^{2}$ ) on $0.5 \mathrm{mg} / \mathrm{L} \mathrm{BP}$ degradation in $\mathrm{UW}$ with $0.1 \mathrm{M}$ $\mathrm{Na}_{2} \mathrm{SO}_{4}$. (A) Concentration-time profiles; (B) Apparent rate constants.

Figure 3. Effect of $\mathrm{BP}$ concentration (in $\mathrm{mg} / \mathrm{L}$ ) on its degradation at $50 \mathrm{~mA} / \mathrm{cm}^{2}$ current density in UW with $0.1 \mathrm{M} \mathrm{Na}_{2} \mathrm{SO}_{4}$. Numbers next to profiles show apparent rate constants (in $1 / \mathrm{min}$ )

Figure 4. Degradation of $0.5 \mathrm{mg} / \mathrm{L} \mathrm{BP}$ at $50 \mathrm{~mA} / \mathrm{cm}^{2}$ current density with $0.1 \mathrm{M} \mathrm{Na}_{2} \mathrm{SO}_{4}$. (A) Various actual water matrices and UW spiked with $10 \mathrm{mg} / \mathrm{L} \mathrm{HA}$; (B) Addition of chloride (in mg/L ) in UW; (C) Addition of bicarbonate (in mg/L ) in UW; (D) Addition of sodium persulfate (in $\mathrm{mg} / \mathrm{L}$ ) in UW; (E) Various initial pH values of UW. (F) Apparent rate constants for runs without (black bars) and with (dashed bars) $1000 \mathrm{mg} / \mathrm{L}$ tert-butanol. Values for runs with butanol have been multiplied by a factor of 100 for clarity.

Figure 5. Effect of low current density $\left(1.4 \mathrm{~mA} / \mathrm{cm}^{2}\right)$ on $0.5 \mathrm{mg} / \mathrm{L}$ BP concentration with $0.1 \mathrm{M}$ $\mathrm{Na}_{2} \mathrm{SO}_{4}$ and various matrices. Dashed line shows experiment without addition of electrolyte.

Figure 6. Degradation of $0.5 \mathrm{mg} / \mathrm{L} \mathrm{BP}$ in UW as a function of SPS ((A) and (B)) or CB ((C) and (D)) concentration. For (A) and (B), CB=25 mg/L; for (C) and (D), SPS=250 mg/L.

Figure 7. Effect of (A) actual water matrix or UW spiked with (B) bicarbonate; (C) humic acid; (D) chloride; (E) methanol; (F) t-butanol on the degradation of $0.5 \mathrm{mg} / \mathrm{L}$ BP with $250 \mathrm{mg} / \mathrm{L}$ SPS and 25 $\mathrm{mg} / \mathrm{L} \mathrm{CB}$. All concentrations in (B)-(F) are in $\mathrm{mg} / \mathrm{L}$. 


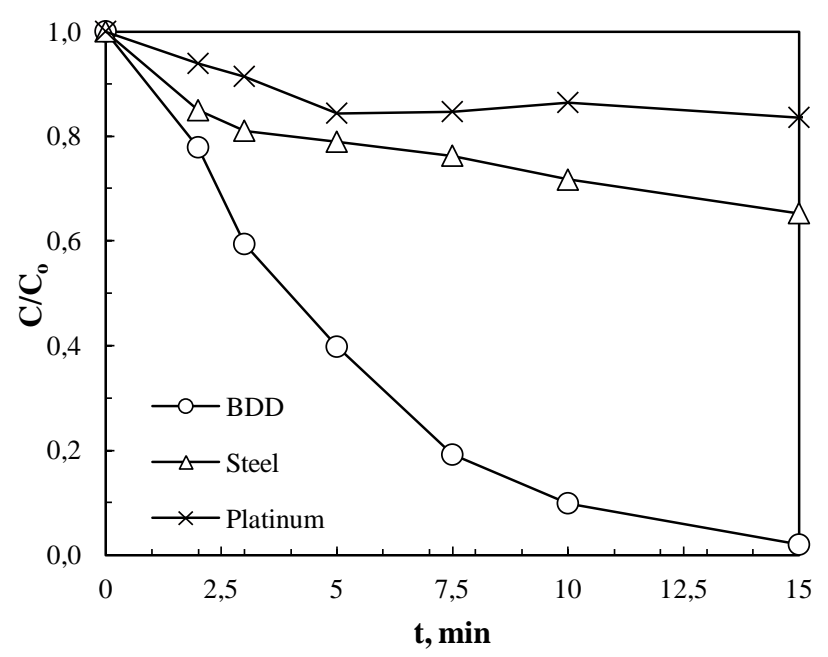

Figure 1. Degradation of $0.5 \mathrm{mg} / \mathrm{L} \mathrm{BP}$ at $50 \mathrm{~mA} / \mathrm{cm}^{2}$ current density with $0.1 \mathrm{M} \mathrm{Na}_{2} \mathrm{SO}_{4}$ in $\mathrm{UW}$ as a function of anodic material. 

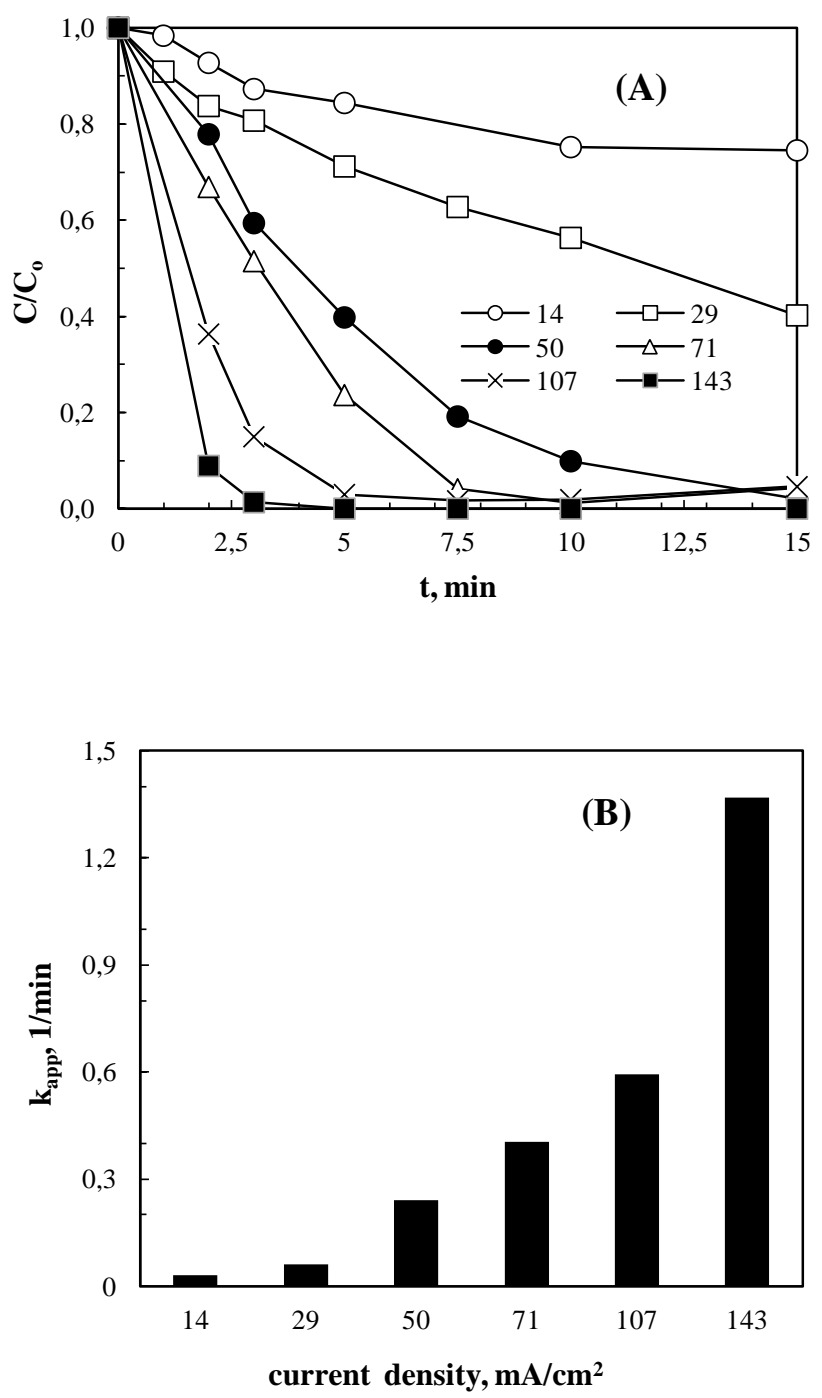

Figure 2. Effect of current density (in $\mathrm{mA} / \mathrm{cm}^{2}$ ) on $0.5 \mathrm{mg} / \mathrm{L} \mathrm{BP}$ degradation in UW with $0.1 \mathrm{M}$ $\mathrm{Na}_{2} \mathrm{SO}_{4}$. (A) Concentration-time profiles; (B) Apparent rate constants. 


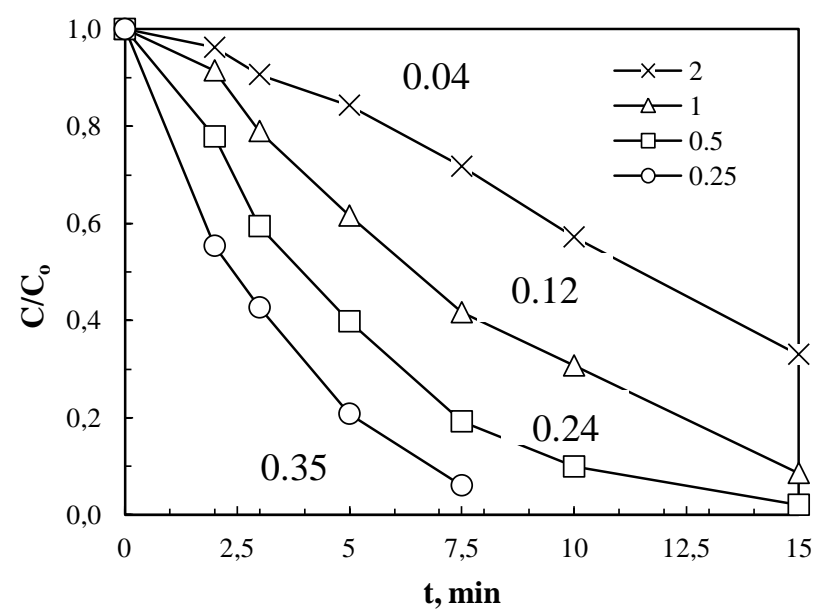

Figure 3. Effect of $\mathrm{BP}$ concentration (in $\mathrm{mg} / \mathrm{L}$ ) on its degradation at $50 \mathrm{~mA} / \mathrm{cm}^{2}$ current density in UW with $0.1 \mathrm{M} \mathrm{Na}_{2} \mathrm{SO}_{4}$. Numbers next to profiles show apparent rate constants (in $1 / \mathrm{min}$ ). 

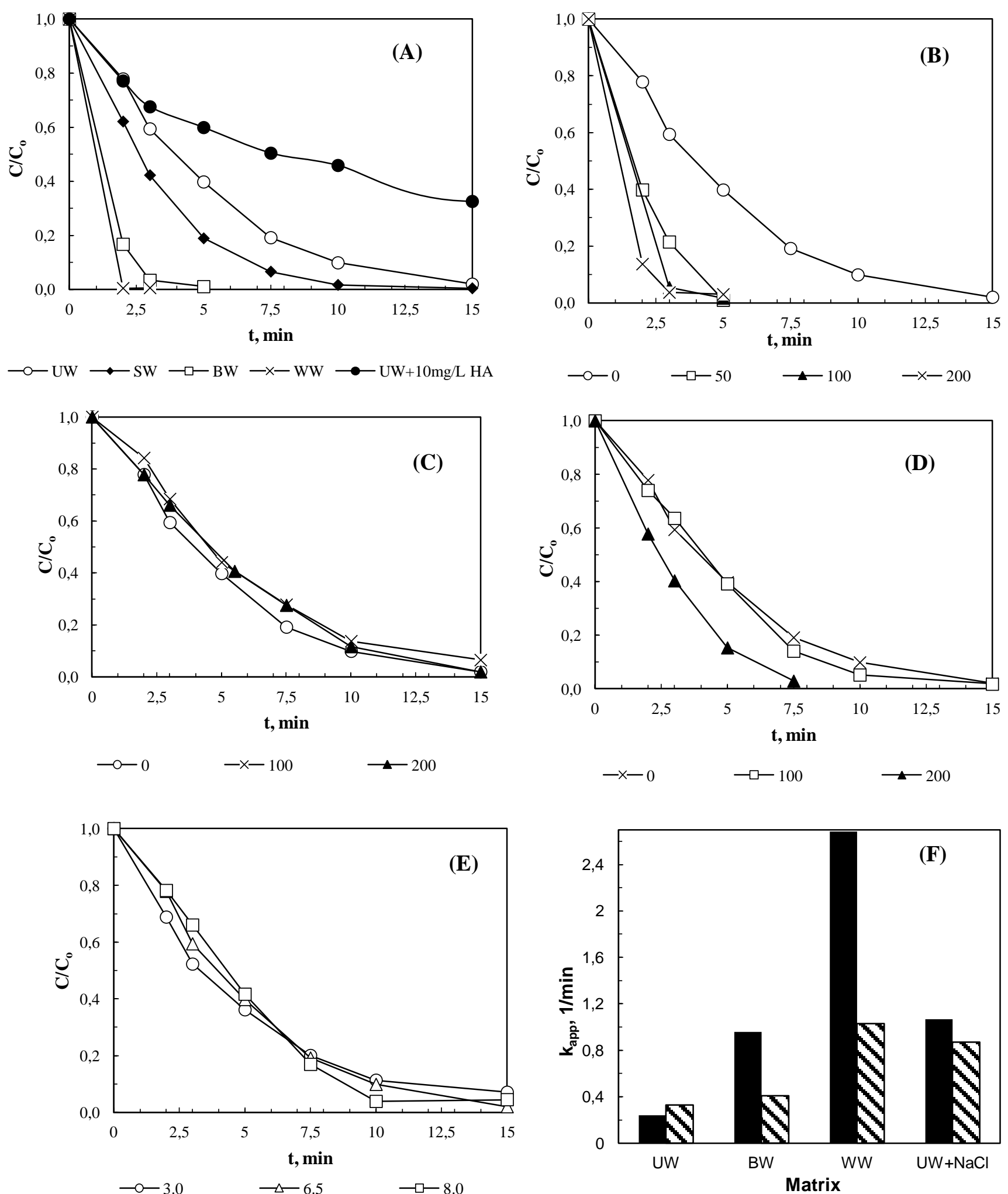

Figure 4. Degradation of $0.5 \mathrm{mg} / \mathrm{L} \mathrm{BP}$ at $50 \mathrm{~mA} / \mathrm{cm}^{2}$ current density with $0.1 \mathrm{M} \mathrm{Na}_{2} \mathrm{SO}_{4}$. (A) Various actual water matrices and UW spiked with $10 \mathrm{mg} / \mathrm{L} \mathrm{HA}$; (B) Addition of chloride (in mg/L ) in UW; (C) Addition of bicarbonate (in $\mathrm{mg} / \mathrm{L}$ ) in UW; (D) Addition of sodium persulfate (in $\mathrm{mg} / \mathrm{L}$ ) in UW; (E) Various initial $\mathrm{pH}$ values of UW. (F) Apparent rate constants for runs without (black bars) and with (dashed bars) $1000 \mathrm{mg} / \mathrm{L}$ tert-butanol. Values for runs with butanol have been multiplied by a factor of 100 for clarity. 


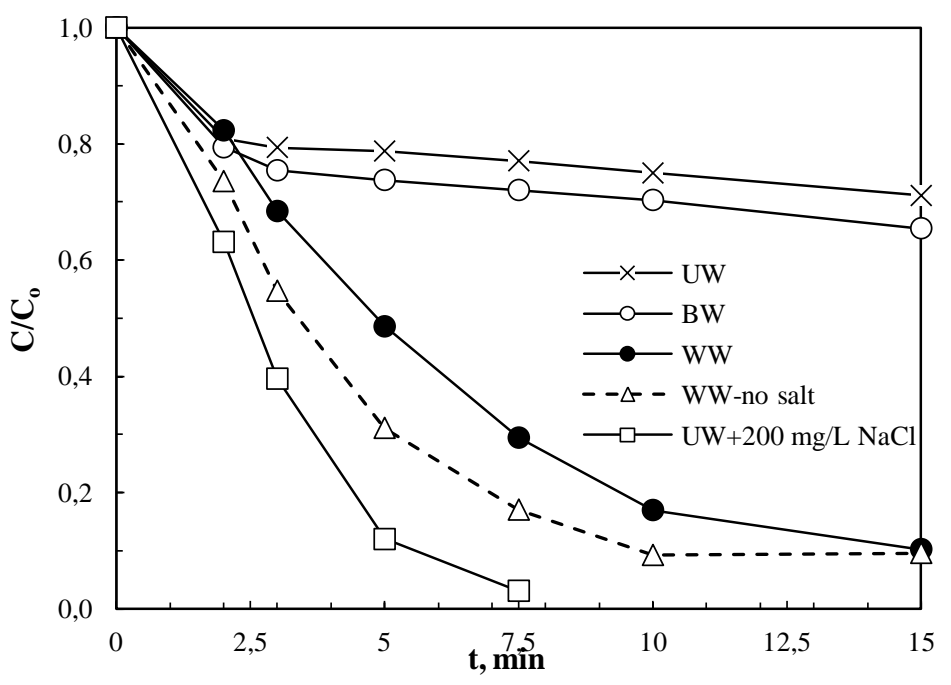

Figure 5. Effect of low current density $\left(1.4 \mathrm{~mA} / \mathrm{cm}^{2}\right)$ on $0.5 \mathrm{mg} / \mathrm{L}$ BP concentration with $0.1 \mathrm{M}$ $\mathrm{Na}_{2} \mathrm{SO}_{4}$ and various matrices. Dashed line shows experiment without addition of electrolyte. 

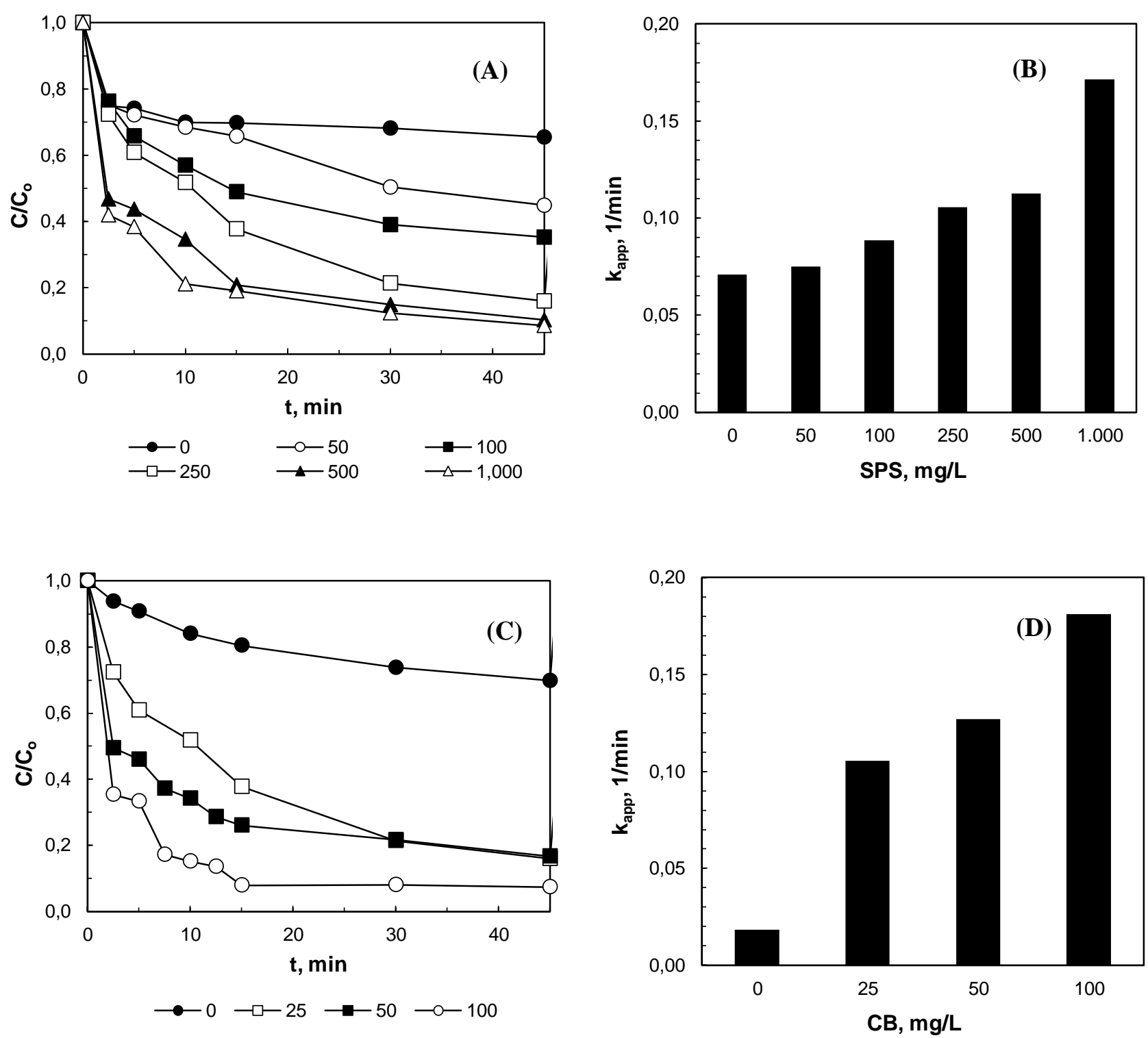

Figure 6. Degradation of $0.5 \mathrm{mg} / \mathrm{L} \mathrm{BP}$ in UW as a function of SPS ((A) and (B)) or CB ((C) and (D)) concentration. For (A) and (B), CB=25 mg/L; for (C) and (D), SPS=250 mg/L. 

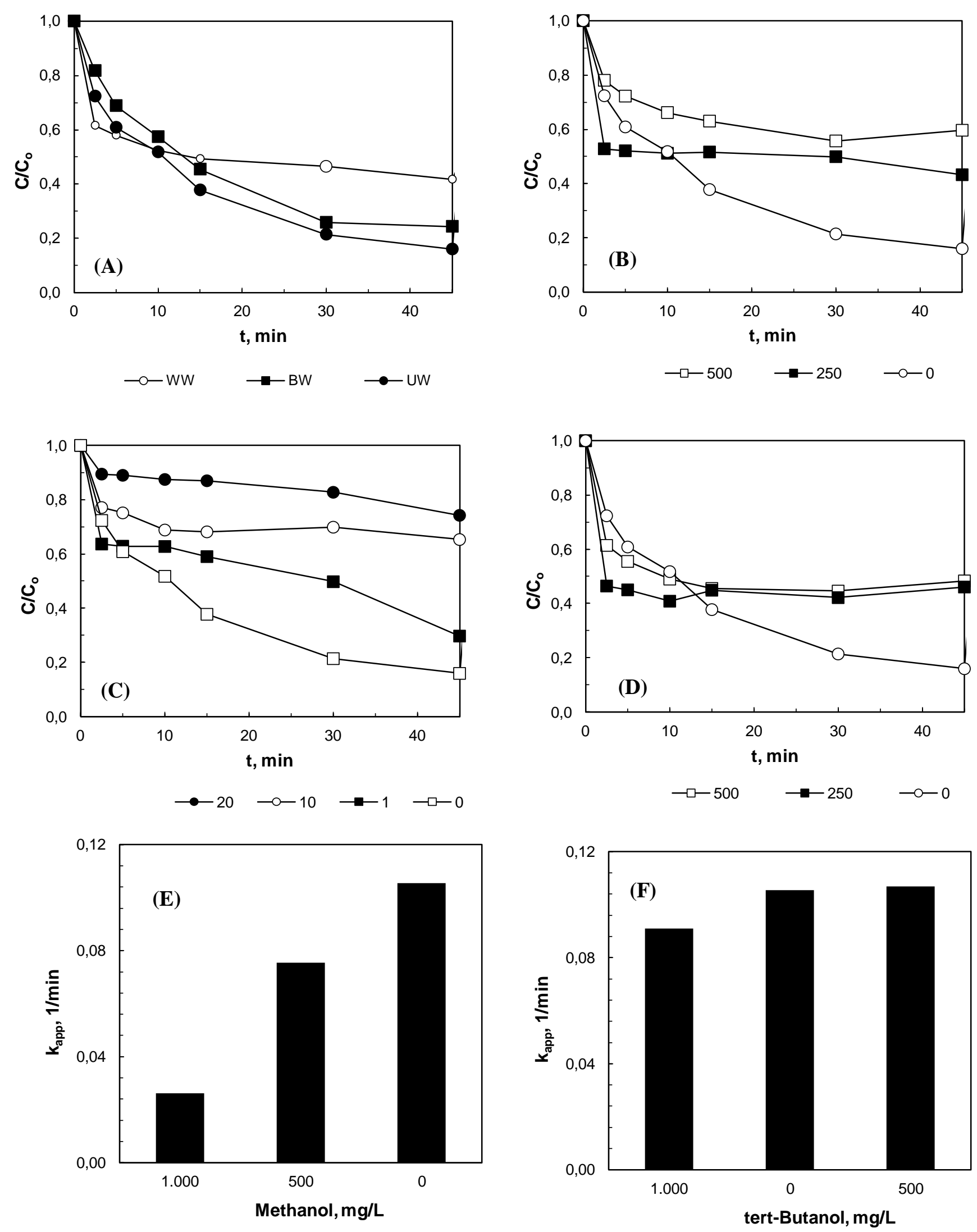

Figure 7. Effect of (A) actual water matrix or UW spiked with (B) bicarbonate; (C) humic acid; (D) chloride; (E) methanol; (F) t-butanol on the degradation of $0.5 \mathrm{mg} / \mathrm{L} \mathrm{BP}$ with $250 \mathrm{mg} / \mathrm{L} \mathrm{SPS}$ and 25 $\mathrm{mg} / \mathrm{L} \mathrm{CB}$. All concentrations in (B)-(F) are in $\mathrm{mg} / \mathrm{L}$. 